\title{
Movement and Home Range of Nile Crocodiles in Ndumo Game Reserve, South Africa
}

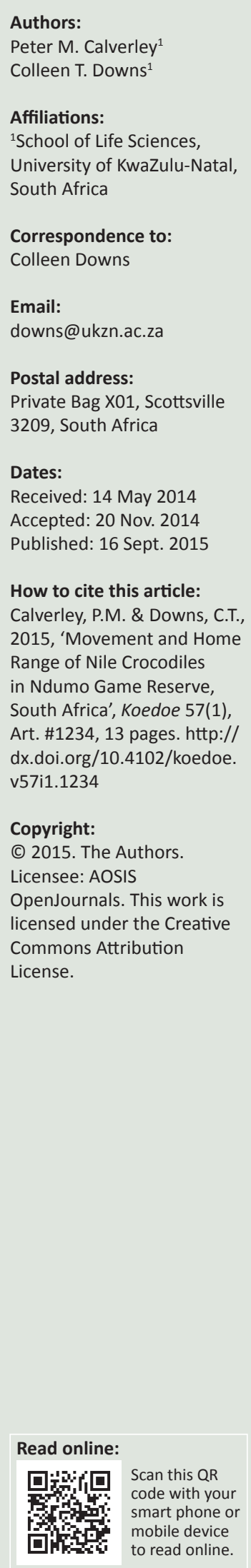

The study of movement patterns and home range is fundamental in understanding the spatial requirements of animals and is important in generating information for the conservation and management of threatened species. Ndumo Game Reserve, in north-eastern KwaZulu-Natal, bordering Mozambique, has the third largest Nile crocodile (Crocodylus niloticus) population in South Africa. Movement patterns of 50 Nile crocodiles with a total length of between $202 \mathrm{~cm}$ and $472 \mathrm{~cm}$ were followed over a period of 18 months, using mark-resight, radio and satellite telemetry. The duration of radio transmitter attachment ( $131 \pm 11.4$ days) was significantly and negatively related to total length and reproductive status. Satellite transmitters failed after an average of $15 \pm 12.5$ days. Home range was calculated for individuals with 10 or more radio locations, spanning a period of at least 6 months. There was a significant relationship between home range size and total length, with sub-adults $(1.5 \mathrm{~m}-2.5 \mathrm{~m})$ occupying smaller, more localised home ranges than adults $(>2.5 \mathrm{~m})$. The largest home ranges were for adults $(>2.5 \mathrm{~m})$. Home ranges overlapped extensively, suggesting that territoriality, if present, does not result in spatially discrete home ranges of Nile crocodiles in Ndumo Game Reserve during the dry season. Larger crocodiles moved farther and more frequently than smaller crocodiles. The reserve acts as a winter refuge and spring breeding site for an estimated 846 crocodiles, which also inhabit the Rio Maputo during the summer months. Nile crocodile movement out of the reserve and into the Rio Maputo starts in November and crocodiles return to the reserve as water levels in the floodplain recede in May.

Conservation implications: Movement patterns of Nile crocodiles show the important role the reserve plays in the conservation of Nile crocodile populations within the greater Ndumo Game Reserve-Rio Maputo area.

\section{Introduction}

The historical range of the Nile crocodile (Crocodylus niloticus) in South Africa included every major river and estuary on the eastern seaboard of the country, extending as far south as the Eastern Cape (Pooley 1982). However, populations are now restricted to the northern and eastern portions of the country between the Limpopo River in the north and the Tugela River in the south (Combrink 2004; Van Vuuren 2011). Viable populations exist exclusively within formally protected areas, such as the Kruger National Park (KNP), Lake St Lucia, Pongolapoort Dam and Ndumo Game Reserve (NGR) (Champion 2011; Combrink 2004; Leslie 1997).

In recent years the crocodile populations in some of these South African rivers and lakes have undergone severe setbacks (Botha et al. 2011; Combrink et al. 2011; Ferreira \& Pienaar 2011). Currently NGR in north-eastern KwaZulu-Natal (KZN) is home to the third largest Nile crocodile population in South Africa (Mathews 1994). It borders on Mozambique and little is known about the movement of Nile crocodiles into surrounding areas, including Mozambique.

Dispersal can be defined as the unidirectional movement of individuals out of the area occupied during the early part of their lives (Hutton 1989). Nile crocodiles generally go through two dispersal events in a lifetime. The first occurs roughly 6-8 weeks after hatching, when hatchlings leave the crèche area (Leslie 1997; Pooley 1969). The second dispersal event occurs when they are $1.2 \mathrm{~m}$ in length (TL), as adults become intolerant of intermediate-sized animals, forcing them to seek new habitat (Hutton 1989). While dispersal involves the unidirectional movement of individuals away from a particular area, migrations are defined by the sequential abandonment and return to an area by a population of animals in response to seasonal changes in resource availability (Swanepoel 1999).

In general, crocodilians do not display migratory behaviour, although the Nile crocodile may be an exception (Russell et al. 2005), with recent studies showing that both C. niloticus and Crocodylus 
porosus have homing capabilities (Combrink 2014; Read et al. 2007). Swanepoel (1999) found that Nile crocodiles in KNP moved between South Africa and Mozambique on a seasonal basis. Pooley (1982) noted similar movement patterns in NGR, where the majority of Nile crocodiles moved between the reserve and the Rio Maputo floodplain in Mozambique on a seasonal basis. There is also evidence that Nile crocodiles undertake large-scale seasonal movements in response to spatial and temporal changes in prey abundance (Leslie 1997). The habitat requirements of Nile crocodiles therefore change on a seasonal basis, which often results in seasonal changes in distribution patterns of a particular population (Botha 2005; Champion 2011).

Home ranges generally centre around suitable basking sites in winter and expand to include favourable breeding (mating and nesting) and foraging sites in summer (Hutton 1989). Adult male Nile crocodiles have the largest home ranges, followed by intermediate males and females (Hutton 1989). The home ranges of reproductive females are focused around nesting sites during the summer and, together with pre-dispersal juveniles ( $<1.2 \mathrm{~m} \mathrm{TL})$, form the smallest home ranges (Hutton 1989). Home ranges of Nile crocodiles are therefore influenced by size or age, sex, season, reproductive status and habitat (Hocutt et al. 1992; Swanepoel 1999).

Studying movement patterns and the distribution of animals is fundamental to understanding basic population processes (Nathan et al. 2008) and is often a prerequisite for effective conservation and management (Rubenstein \& Hobson 2004). Movement studies normally consist of four key components, namely dispersal, migration, territoriality and home range (Swanepoel 1999). Consequently, in the current study, we used telemetry and capture-resight techniques to investigate the spatial and movement ecology of Nile crocodiles in NGR, in order to assist with their management and conservation.

The aim of this study was to quantify home range, migration and territoriality of Nile crocodiles in NGR. In particular, seasonal changes in habitat use and movement, and whether crocodiles moved out of the reserve and into unprotected areas and Mozambique, were investigated. It was predicted that home ranges were influenced by season, size and sex of crocodiles and that seasonal migration from NGR into the Rio Maputo floodplain took place over the wet season.

\section{Methods}

\section{Study site}

Ndumo Game Reserve is a relatively small (10000 ha) Ezemvelo KZN Wildlife (EKZNW) game reserve in northeastern KZN. It conserves two major river systems: The Usuthu River forms the northern boundary of the reserve and the southern boundary of Mozambique, while the Pongola River and floodplain run along the eastern boundary of NGR (Figure 1). The confluence of these two river systems in the north-eastern corner of NGR and the flat nature of the floodplain combine to inundate large tracts of NGR with water during times of high rainfall. During an average dry season, roughly $12 \%$ of the surface area of NGR is covered by water in the form of permanent pans and river courses. During the wet season, over $40 \%$ of NGR becomes inundated with water (Calverley 2013).

The Usuthu system consists primarily of the Usuthu River, the Banzi Pan area and Shokwe Pan (Figure 1). The Pongola system consists of the Pongola floodplain and Lake Nyamithi (Figure 1). The largest permanent pan in the Pongola floodplain is Lake Nyamithi (157 ha), which has the highest density of Nile crocodiles in NGR (Figure 1) and forms the focal point of this study, where seasonal variation in abundance was recorded. Further details and description of the study area are presented elsewhere (Calverley 2013; Calverley \& Downs 2014a, 2014b).

\section{Capture techniques}

All Nile crocodiles captured in NGR were caught in Lake Nyamithi (Figure 1). During winter the deepest part of the lake is an average of $2.8 \mathrm{~m}$ deep, while the average depth of the lake is $0.98 \mathrm{~m}$ (Dutton 1971). The shallow nature of the lake and high density of crocodiles favour noosing as a capture technique, as described by Hutton and Woolhouse (1989). Crocodiles were approached at night from a $3.5 \mathrm{~m}$-long aluminium boat powered by a $35 \mathrm{hp}$ Mercury motor (Fond du Lac, Wisconsin). Individuals were spotted using two onemillion candlepower Coleman spotlights (Golden, Colorado) powered by a Deltec deep cycle $12 \mathrm{~V}$ battery (Johannesburg, South Africa). A $3 S 183 \mathrm{~cm}$ Thompson self-locking steel snare was positioned around the animal's neck using a 3 m-long aluminium pole, to which it was attached using Duct tape. Once pulled tight, the snare locked in place and became detached from the aluminium pole. The crocodile was retrieved using a $12 \mathrm{~mm}$ diameter nylon ski rope that was attached to the snare using a lock-gate karabiner.

Nile crocodiles that submerged upon the approach of the boat were often spotted under the clear water and harpooned, as described by Webb and Messel (1977). Harpooned crocodiles were then pulled to the surface and noosed, as described above. Harpooning was only initiated in 2012. During 2012, in order to be more selective and to capture during the day, heavy duty angling equipment was used to catch crocodiles. A barbless treble hook set in lead was cast over a crocodile seen swimming or floating in the lake. The line was then reeled in, with the intention of hooking the crocodile on the neck or side.

When 'fishing' from the shore, it was sometimes necessary to wade out and secure the neck of the crocodile with a noose, as described above, as the crocodile used its feet to dig into the substrate or was too big to reel in. It was therefore necessary to fish for crocodiles from a boat where close proximity to the individual was achieved without having to enter the water. If the crocodile dug in, the boat was pulled towards the animal by reeling in. Once positioned above the crocodile, it was either noosed (if the head or tail broke the surface) or it was harpooned. Fishing necessitated the use of 


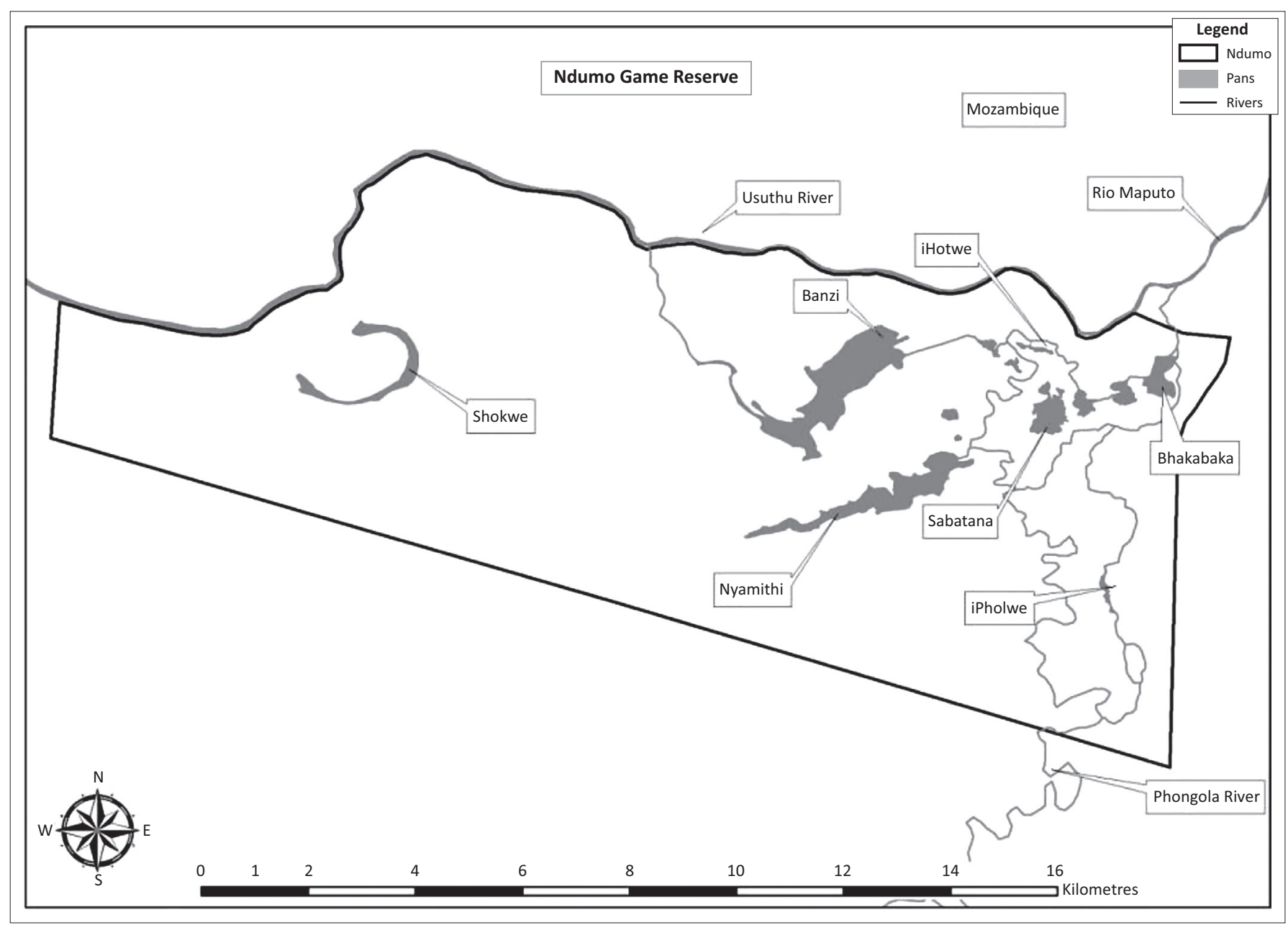

Source: Authors' own creation

FIGURE 1: The Ndumo Game Reserve, KwaZulu-Natal, South Africa, showing the major pans and rivers that make up the hydrology of the reserve.

heavy angling equipment. Accordingly, a Penn Power Stick Rod (Philadelphia, USA) with a large coffee grinder reel was used (Fin-Nor ${ }^{\circledR}$ Offshore, USA), having a $400 \mathrm{~m} 80 \mathrm{lb}$ braided fishing line, which was attached to $200 \mathrm{lb}$ Marlin monofilament nylon.

Regardless of the capture technique, all captured Nile crocodiles were taken ashore for morphometric measurements and were uniquely scute notched for permanent long-term identification. They were then fitted with a unique sequence of coloured tags for short-term visual identification before being released. A unique colour-coded sequence of three standard livestock plastic ear tags were attached to three vertical tail scutes by drilling a single hole through each scute and securing each tag with two cable ties. The location of the capture site was recorded using a Garmin eTrex Vista ${ }^{\circledR} \mathrm{CX}$ Global Positioning System (GPS) (Kansas, USA). Animals fitted with radio and satellite transmitters took an average of $50 \mathrm{~min}$ to process, while those being scute notched and tagged took an average of $20 \mathrm{~min}$.

\section{Transmitter attachment}

Very high frequency (VHF) transmitters (150 MHz) were fitted to 10 Nile crocodiles of varying size and sex.
Transmitters were attached between the four nuchal scutes on the nuchal plate, as described by Kay (2004b). The transmitters were seated between the four vertical scutes and secured using cable ties that ran through holes drilled into the four vertical scutes. Dental acrylic (Vertex) was used to mould around and under the transmitters to strengthen the platform of attachment.

Three satellite transmitters, supplied by Africa Wildlife Tracking (Pretoria, South Africa), were fitted to Nile crocodiles: two in 2011 and one in 2012. Following mixed success with the method described by Kay (2004a) with radio transmitters, satellite transmitters were attached using the method described by Brien et al. (2010).

Transmitters were placed between the four nuchal scutes and attached to the nuchal shield using stainless steel wire $(1 \mathrm{~mm}$ in diameter), which ran under the nuchal plate and through attachment tubes in the transmitters. Dental acrylic was then moulded around the transmitter, encasing the stainless steel wires. Our method differed from Brien et al. (2010) in that the subject was physically and not chemically immobilised. The nuchal area was anesthetised by injecting a local anaesthetic, 2\% lignocaine hydrochloride (Bayer, Isando, South Africa), under the nuchal shield (Kay 2004a). 


\section{Radio and satellite tracking}

Thirty-one tracking excursions were undertaken from March to November 2009. After November 2009, radio transmitters were no longer able to be located due to detachment or movement of crocodiles into Mozambique and out of range of the receiver and antennae. Search time varied from individual to individual and not all radio-tagged crocodiles were located on all tracking excursions.

Radio-tagged animals were located using an Alinco DJ-X10 receiver (Tokyo, Japan), which was attached to a unidirectional Yagi antenna. The location was recorded using a Garmin eTrex Vista ${ }^{\circledR}$ CX GPS. Movement patterns of Nile crocodiles with satellite transmitters were followed remotely by accessing the Africa Wildlife Tracking website (http://www.awt.co.za/). Recording intervals were initially set for every $8 \mathrm{~h}$, and were displayed on Google Maps and available as GPS coordinates.

\section{Mark-resight}

Between March 2009 and November 2010, diurnal counts were carried out at Lake Nyamithi for mark-resight observations. A vehicle was driven around the $9.5 \mathrm{~km}$ periphery of the lake with an average search time of $2 \mathrm{~h} 53 \mathrm{~min}$. The date, time and duration of the survey as well as weather conditions were recorded. Minimum and maximum temperature, humidity and rainfall data were collected at NGR Head Office, $5 \mathrm{~km}$ south-east of Lake Nyamithi. The identification and location of tagged Nile crocodiles were recorded using a Garmin eTrex Vista ${ }^{\circledR}$ CX GPS.

By 2011, some or all of the coloured tags fitted to crocodiles had either dislodged or were indiscernible due to a covering of mud or algae. Permission was not granted to attach further tags to crocodiles by EKZNW as it was deemed that a representative amount of the population had been tagged.

\section{Statistical analyses}

Seaman and Powell (1996) found that the kernel method, with cross validation as a smoothing factor, was the most accurate method of estimating home range. Additionally, using the fixed kernel method for estimating home range, and leastsquares cross-validation (LSCV) to calculate the smoothing factor, provides the most accurate and least biased estimates (Seaman et al. 1999). However, while fixed kernel density estimates (KDEs) provide the most accurate fit (Worton 1989), minimum convex polygons (MCPs) most closely follow Burt's (1943) definition of home range. Furthermore, MCPs have been used to calculate crocodilian home range due to the robustness of this method when dealing with autocorrelated data (Kay 2004a, 2004b; Rootes \& Chabreck 1993). Since some of the data was significantly autocorrelated (Schoener Index $<1.6>2.4$; Swihart and Slade Index $>0.6$ ), MCPs as well as KDEs were determined for all samples.

The majority of locations achieved through VHF tracking and all of the mark-resight locations were obtained on the water margin. This can be problematic in sinuous waterways, in lakes with large bays or outcrops and where few geographic fixes or locations are available, as MCPs and KDEs include large amounts of terrestrial habitat that are not used by crocodiles.

River Channel Area (RCA) and Mid-Stream Linear Distance (MSLD) have been used to calculate Nile crocodile home ranges when the number of fixes is low or the terrain makes other methods unsuitable (Brien et al. 2008). However, in NGR, crocodiles make use of lacustrine and riverine habitat, therefore RCAs and MSLDs would not provide appropriate home range estimations for the portion of time spent in pans or lakes. As a comparison, it was decided to manually draw our own MCPs using shorelines and river banks as boundaries between locations that were on shorelines. Using this method, terrestrial habitat was not included in calculating the home range.

Nile crocodiles with more than 10 radio fixes were selected for analysis $(n=8$; mean fixes $=17 \pm 1.27)$. Seaman et al. (1999) suggest a minimum of 30 geographic fixes are required when using LSCV for smoothing in the fixed kernel method, while 100-300 fixes may be necessary before an asymptote is reached using MCP analysis. However, Hutton (1989) found that the home range of Nile crocodiles $>2.2 \mathrm{~m}$ could be defined in 20-25 fixes, while breeding females required 35-45 fixes in a seasonal river in Zimbabwe.

Nile crocodiles are notoriously hard to monitor using radio telemetry, mostly due to transmitter attachment or operation failures (Botha 2005; Strauss et al. 2008; Swanepoel 1999). This, combined with the seasonal occupation of NGR by Nile crocodiles (Pooley 1969), our number of radio locations, although lower, should provide a reasonable estimate of home range during the dry season when crocodiles are mostly restricted to Lake Nyamithi.

Home range size was estimated using the Home Range Extension (Rodgers \& Carr 1998) for ArcGIS ${ }^{\oplus}$ 9.3.1 (ESRI, Redlands, USA). Fixed KDEs were used to calculate 95\%, $90 \%$ and $50 \%$ polygons using LSCV as the smoothing factor. Similarly, fixed mean MCPs were constructed for 95\%, $90 \%$ and $50 \%$ contours. A one-way analysis of variance (ANOVA) was run in STATISTICA 7.0 (Statsoft, Tulsa, USA) to determine any significant differences in home range size between male and female, and breeding and non-breeding Nile crocodiles in the dry season. One-way ANOVAs were suitable in determining the effect of a single categorical independent variable (sex or reproductive status) on the home range of Nile crocodiles.

A simple regression was run as a general linear model (GLIM) to check for significant influences of length on the home range size of Nile crocodiles. General linear model ANOVAs were run to test for differences in home range estimates produced by the KDEs, MCPs and manually drawn polygons. All mean values were presented as mean \pm standard error (standard error). Significance was assessed at a p value of 0.05 . 
In this study, transmission failure was taken as a sign of attachment failure, unless the individual was later observed with a transmitter attached. In both cases, the date of the last radio fix or visual sighting with the transmitter attached was taken as the day of detachment. One-way ANOVAs were run to determine any significant relationships between transmitter longevity and sex. A simple regression was run as a GLIM to check for significant influences of TL on transmitter longevity.

\section{Results}

\section{Catching and fitting of transmitters}

The majority of Nile crocodiles captured $(82 \%)$ were caught using the noosing technique. Twelve crocodiles (9\%) were caught using the harpoon method and six crocodiles using angling equipment $(4 \%)$. This does not indicate the efficacy of the different capture methods, as harpooning and angling equipment were only introduced in 2012, while noosing was used throughout the study. No crocodiles were caught using baited traps.

Between March and May 2009, ten Nile crocodiles caught were fitted with radio transmitters at Lake Nyamithi. This consisted of seven males $234 \mathrm{~cm}-358 \mathrm{~cm}$ TL and three females $202 \mathrm{~cm}-281 \mathrm{~cm}$ TL (Table 1). Between March 2009 and November 2010, a further 88 crocodiles were caught and fitted with coloured tags for mark-resight. Of these, 45 were females $100 \mathrm{~cm}-319.4 \mathrm{~cm}$ TL and 43 were males $84.3 \mathrm{~cm}-$ $472 \mathrm{~cm}$ TL.

\section{Radio tracking to show movements}

Between March 2009 and November 2009, thirty-one radio tracking excursions were undertaken. Not all 10 individuals were located during a particular excursion and the highest number of fixes for an individual over this period using radio telemetry was 23, for a $202 \mathrm{~cm}$ TL female. The lowest number of radio locations was 5, for a $259 \mathrm{~cm}$ TL male that ranged widely throughout the floodplain, often out of range of the VHF signal. The average number of fixes for the telemetered crocodiles was 17 (SE \pm 1.27$)$. From December 2009 onwards, no signal could be obtained for the radiotagged crocodiles.
In NGR in winter, Nile crocodile movements for individuals $\leq 202 \mathrm{~cm}$ TL were mostly restricted to Lake Nyamithi (Appendix 1 and 2). Larger individuals spent the majority of their time within the lake, but made numerous and extensive forays into the Pongola floodplain and to the new course of the Usuthu River below Banzi Pan, returning to Lake Nyamithi thereafter (Appendix 1 and 2). Only one of the telemetered Nile crocodiles captured in the Pongola system ventured into the Usuthu River system or Banzi Pan.

\section{Mark-resight}

Between March 2009 and October 2010, twenty-seven mark-resight exercises were carried out at Lake Nyamithi. After October 2010, flooding of the lake made accessibility impossible. In total, 131 observations of 37 tagged Nile crocodiles were made, with a highest resighting of 10 for an individual and a mean of $3.4 \pm 0.42$ for 37 resighted individuals. Mark-resight results did not produce enough locations to run home range analyses, but did add to $(n=17)$ data on radio-tracked Nile crocodiles once transmitters had fallen off.

No marked individuals were observed in NGR during the summer months. This was partially due to the inaccessibility

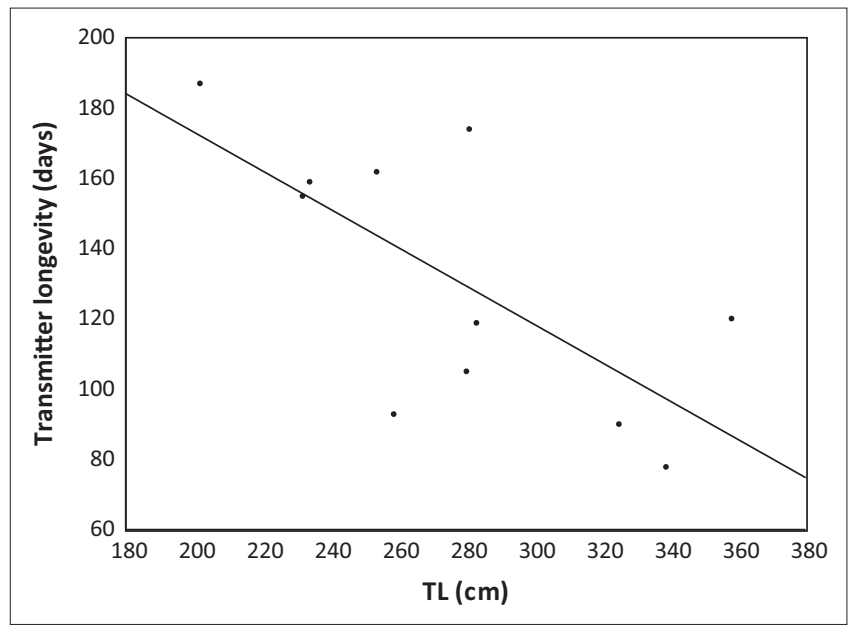

$\mathrm{TL}$, total length in centimetres.

FIGURE 2: Scatter plot showing the relationship between transmitter attachment longevity and total length of Nile crocodiles at Ndumo Game Reserve.

TABLE 1: Radio and mark-resight occurrences of 10 Nile crocodiles (202 cm - $358 \mathrm{~cm}$ total length) over a 7-month period (March 2009- November 2009) in Ndumo Game Reserve.

\begin{tabular}{|c|c|c|c|c|c|c|}
\hline Number crocodile & Sex & Capture date & $\mathrm{TL}(\mathrm{cm})$ & Number fixes & Resight & Transmitter loss \\
\hline 26 & Female & 03-05-2009 & 283 & 7 & 0 & 09-2009 \\
\hline 10 & Female & 28-03-2009 & 232 & 12 & 0 & 03-09-2009 \\
\hline 25 & Male & 02-05-2009 & 358 & 16 & 0 & 09-2009 \\
\hline 8 & Male & 27-03-2009 & 280 & 7 & 0 & $11-07-2009$ \\
\hline 24 & Male & 02-05-2009 & 325 & 10 & 4 & 08-2009 \\
\hline 3 & Female & 26-03-2009 & 202 & 27 & 1 & $11-2009$ \\
\hline 11 & Male & 29-05-2009 & 259 & 15 & 0 & 09-2009 \\
\hline 23 & Male & 01-05-2009 & 281 & 16 & 6 & $22-10-2009$ \\
\hline 1 & Male & 24-03-2009 & 234 & 18 & 0 & 09-2009 \\
\hline 6 & Male & 26-03-2009 & 339 & 6 & 10 & $12-06-2009$ \\
\hline 7 & Male & 27-03-2009 & 254 & 17 & 0 & 06-09-2009 \\
\hline
\end{tabular}

$\mathrm{TL}(\mathrm{cm})$, total length in centimetres. 
of Lake Nyamithi because of high water levels and also because of the majority of crocodiles leaving the lake to enter the floodplain and possibly Mozambique (Calverley 2013).

\section{Home range}

Only home range estimated using KDEs showed significant relationships between home range size and TL of Nile crocodiles. Core home range (GLIM ANOVA, $F_{(1,5)}=10.09$, $P=0.024), 90 \%$ (GLIM ANOVA, $\left.F_{(1,5)}=7.07, P=0.045\right)$ and $95 \%$ (GLIM ANOVA, $F_{(1,5)}=6.81, P=0.048$ ) home range estimates were significantly related to TL (Figure 2). Adult Nile crocodiles occupied larger home ranges (2200.7 ha \pm 373.45 ha) than sub-adults (419.4 ha \pm 466.77 ha) for the $95 \%$ polygons (ANOVA, $F_{(1,7)}=21.51, P=0.035$, Figure 3a). Core

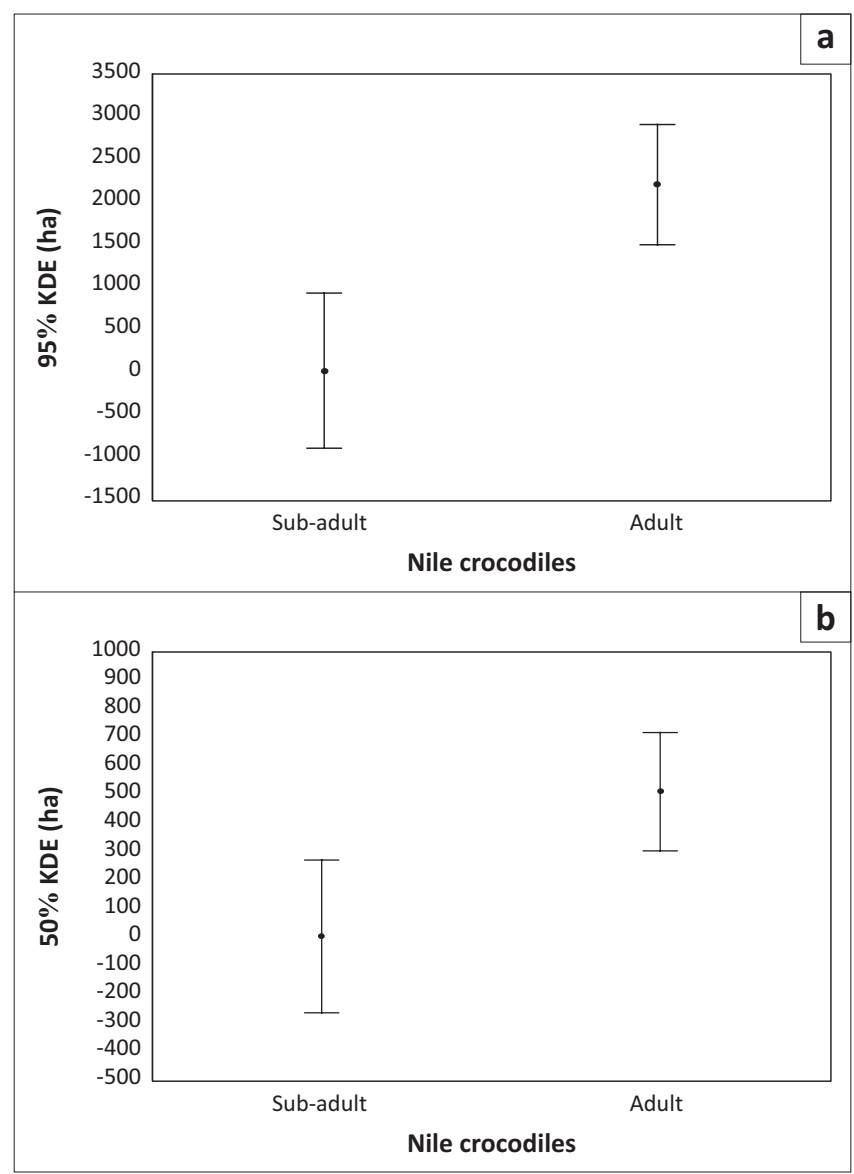

$\mathrm{KDE}$, kernel density estimates.

FIGURE 3: Home range of Nile crocodiles at Ndumo Game Reserve where a. is mean (+ standard error) home range ( $95 \%$ kernel density estimates) of subadults $(n=3)$ and adults $(n=5)$; and $\mathrm{b}$. is mean (+ standard error) core home range for adults $(n=5)$ and sub-adults $(n=3)$ with $\pm 95 \%$ confidence intervals. area (50\% polygon) used by adults was also larger (510.4 ha \pm $98.90 \mathrm{ha})$ than sub-adults $(2.4 \mathrm{ha} \pm 3.26 \mathrm{ha})$ (ANOVA, $F_{(1,6)}=$ $13.43, P=0.011$, Figure $3 b)$.

On average, core home range use ( $50 \%$ polygon) of subadult Nile crocodiles $(n=4)$ formed $19.9 \%$ of the $95 \%$ kernel estimation (e.g. Hutton 1987), while those of adult Nile crocodiles $(n=4)$ formed $24 \%$ of the $95 \%$ kernel estimation. Ninety per cent home range polygons of sub-adult Nile crocodiles $(n=4)$ formed $77.3 \%$ of the $95 \%$ kernel estimation and $95 \%$ home range polygons of adult Nile crocodiles $(n=4)$ formed $79.0 \%$ of the $95 \%$ kernel estimation.

\section{Transmitter attachment longevity}

Radio transmitters $(n=10)$ lasted on average 131 (SE \pm 11.4 ) days on Nile crocodiles in NGR before becoming dislodged or failing to transmit. The duration of transmitter attachment was significantly related to size (TL) (GLIM ANOVA, $F_{(1,9)}=$ $8.54, P=0.02)$.

Nine of the ten transmitters were dislodged between August and November 2009, which coincided with the onset of the breeding season in NGR. Four transmitters were recovered, two of which had visible bite marks. Transmitters were found still embedded in the dental acrylic and with the cable ties attached. Cable ties had not broken on any of the transmitters and attachment failure was due to poor bonding between the acrylic and the nuchal plate, and the cable ties wearing through the four ventral scutes. For example, Crocodile 150.196 gave ample opportunities for observation on cable ties pulling through the scutes until only one cable tie was holding the transmitter in place. Soon after, the transmitter was dislodged completely and recovered. From these observations it was clear that the dental acrylic did not bond to the nuchal plate from the outset.

Satellite transmitters lasted an average of 15 days (SE \pm $12.5, n=3$ ) on Nile crocodiles in NGR. No transmitters were recovered.

\section{Discussion}

Improvements in tracking technologies are allowing for more accurate studies on movement and home range of wildlife. However, in many instances, attachment and reliability remain a problem (Lang \& Whitaker 2010; Strauss et al. 2008, Thomas et al. 2011).

TABLE 2: Home range estimates for 8 Nile crocodiles $(202 \mathrm{~cm}-358 \mathrm{~cm}$ total length) in Ndumo Game Reserve.

\begin{tabular}{|c|c|c|c|c|c|}
\hline Size $(\mathrm{cm})$ & Sex & Frequency & 95\% kernel (ha) & $\mathbf{9 0} \%$ kernel (ha) & $50 \%$ kernel (ha) \\
\hline 202 & $\mathrm{~F}$ & 237 & 3.2 & 2.4 & 0.6 \\
\hline 232 & $\mathrm{~F}$ & 455 & 36.7 & 27.6 & 8.0 \\
\hline 234 & $M$ & 196 & 5.7 & 4.5 & 1.2 \\
\hline 254 & $M$ & 215 & 1631.9 & 1266.1 & 288.1 \\
\hline 281 & $M$ & 276 & 2750.7 & 2145.2 & 555.6 \\
\hline 315 & $M$ & 295 & 2244.6 & 1787.9 & 595.0 \\
\hline 339 & $M$ & 316 & 1221.6 & 961.4 & 280.6 \\
\hline 358 & $M$ & 396 & 3154.6 & 2521.6 & 832.8 \\
\hline
\end{tabular}


General findings indicate that crocodilians are capable of travelling farther than previously thought (Campos et al. 2006; Combrink 2014; Combrink et al. 2013; Read et al. 2007; Swanepoel 1999), while home range size is strongly influenced by topography, reproductive status, season and size of individuals (Brien et al. 2008). It is necessary to discuss the movement ecology of Nile crocodiles within this context and in comparison with movement studies conducted on other crocodilian species.

\section{Telemetry}

High rates of transmitter loss and detachment in crocodilians has been attributed to intraspecific social interactions, particularly during the breeding season (Strauss et al. 2008). In NGR, courtship takes place from early August into September (Calverley 2013; Pooley 1982). During this period the majority of transmitters on Nile crocodiles in NGR were dislodged, suggesting that courtship and possible mate competition behaviour were the primary cause of attachment failure.

Despite larger crocodiles having more pronounced nuchal scutes, which form a better attachment location (Franklin et al. 2009), the attachment period was negatively related to TL. Although Strauss et al. (2008) postulated that ultraviolet exposure may compromise cable tie strength, we found that the reason for dislodgment was the inadequacy of the nuchal scutes as an attachment site. We are in agreement with Strauss et al. (2008) that further attachment methods need to be investigated, such as bone pins into the osteoderms, a better adhesive or subcutaneous attachment (Franklin et al. 2009; Kay 2004a).

\section{Movement patterns within seasons}

Movement patterns of crocodilians generally constrict during the dry season (Campos et al. 2006; Hocutt et al. 1992; Thomas et al. 2010). Radio transmitters fitted to Nile crocodiles in NGR showed that dry season movements for individuals $\leq 202 \mathrm{~cm}$ TL were mostly restricted to Lake Nyamithi. Larger individuals spent the majority of their time within the lake, but made extensive forays into the floodplain, returning to Lake Nyamithi thereafter. Extensive movement during winter is unusual in crocodiles (Hocutt et al. 1992; Hutton 1989).

Lake Nyamithi is well stocked with fish (personal observation [pers. obs.]) and crocodiles feed less in winter (Games 1990; Wallace \& Leslie 2008). It is therefore unlikely that movement out of the lake is due to foraging behaviour. Furthermore, the lake provides excellent basking habitat (Pooley 1982), with aggregations of up to and exceeding 100 animals in a single locality observed (pers. obs.).

Extensive and repeated movement out of the lake comes at a high energetic cost during winter, when ectotherms normally try to conserve energy through behavioural thermoregulation (Downs et al. 2008). Cyclic movement out of Lake Nyamithi did not coincide with the breeding or nesting season; consequently, it is unlikely that reproduction plays a role in these movement patterns.

One possible explanation could be due to rising salinity levels in Lake Nyamithi during the dry season. In summer, salinity levels range from $200 \mathrm{ppm}$ to $900 \mathrm{ppm}$ in a gradient running from the outlet in the east to the inlet in the west (Forbes \& Demetriades 2006). However, during winter, evaporation exceeds precipitation and, combined with the intrusion of saline water through ground seepage, salinity levels rise to anything from $5630 \mathrm{ppm}$ in the middle of the lake to $11290 \mathrm{ppm}$ at the inlet (sea water is $35000 \mathrm{ppm}$ ) (Heeg \& Breen 1982).

Although Nile crocodiles are considerably more euryhaline than previously thought, periodic access to fresh water is considered essential for survival in saline conditions and osmoregulation is often achieved behaviourally through the selection of fresh water habitats (Combrink 2014; Leslie \& Spotila 2000). Movement out of Lake Nyamithi and into the fresh water of the Pongola and Usuthu River channels could be a behavioural osmoregulatory response.

\section{Movement patterns between seasons}

Seasonal changes in habitat use of crocodiles is common and often results in seasonal changes in movement patterns (Botha 2005; Champion 2011; Hutton 1989; Leslie 1997; Modha 1967; Pooley 1982; Swanepoel 1999). In winter or during the dry season, movement is mostly nocturnal and is focused around basking sites (Hutton 1989). In summer, movement is diurnal and is often related to foraging activities.

Transmitters did not stay attached or transmit during both the wet and dry seasons, making it difficult to assess seasonal changes in movement patterns in NGR. However, after monthly changes in the abundance of Nile crocodiles in Lake Nyamithi, numbers drop from a peak of around 400 in July to 60 in November. Numbers only start to increase again in April (Calverley 2013; Calverley \& Downs 2014a, 2014b). Nile crocodiles, therefore, move out of Lake Nyamithi during the wet season and return in the dry season.

Total population estimates for the entire reserve during November have shown an absolute abundance of 377 Nile crocodiles in the reserve, while the winter estimate is close to 850 (Calverley 2013; pers. obs.), suggesting that this movement is not only out of Nyamithi, but out of the reserve as well. A survey of the Rio Maputo in mid-November 2010 showed an absolute abundance of 242 crocodiles (Fergusson 2010), while a survey conducted in NGR in early November 2011 yielded only 28 individuals over this same area. It is likely that movement out of the reserve and into Rio Maputo takes place from early November onwards. Some of the crocodiles counted by Fergusson (2010) were as far as $90 \mathrm{~km}$ from the reserve. This constitutes a significant movement that would be the farthest recorded for the species if they originated from the reserve. There is, however, no direct 
evidence that this is the case and further telemetric studies would be necessary to quantify the extent of movement between NGR and the Rio Maputo floodplain.

Large-scale seasonal movement or migration in reptiles is uncommon and usually attributed to a return to thermal refugia or breeding sites as well as seasonal changes in prey availability (Madsen \& Shine 1996). Generally, crocodilians do not display migratory behaviour, although the Nile crocodile may be an exception (Russell et al. 2005), with recent studies showing that both $C$. niloticus and C. porosus have homing capabilities (Combrink 2014).

Swanepoel (1999) found that Nile crocodiles in KNP move up to $36 \mathrm{~km}$ between South Africa and Mozambique on a seasonal basis. Pooley (1982) noted similar movement patterns in NGR, where the majority of Nile crocodiles moved between the reserve and the Rio Maputo floodplain in Mozambique on a seasonal basis, presumably for nesting purposes. Nile crocodiles are known to return to historical nesting sites, which could induce a seasonal migration, as suggested by Pooley (Combrink 2014).

The movement of Nile crocodiles into NGR from the Rio Maputo floodplain during winter could therefore be for thermoregulatory reasons, while the movement out of NGR during the wet season could be related to foraging or nesting requirements, since mating takes place within the reserve. However, male and female crocodiles also leave the reserve during the wet season, indicating that something other than the presence of favourable nesting habitat is triggering movement into the Rio Maputo floodplain. Furthermore, nesting surveys carried out in NGR (Calverley 2013) indicated that suitable nesting habitat was not in short supply within NGR, and the abundance of juvenile and subadult crocodiles in Lake Nyamithi suggested that a degree of localised nesting does occur within the reserve.

Crocodiles are highly adept at exploiting ephemeral prey resources such as concentrations of fish (pers. obs.; Webb et al. 1982) and where such prey concentrations occur seasonally, large-scale seasonal movement or migration of crocodiles could be expected. Furthermore, crocodiles feed more in summer than in winter (Wallace \& Leslie 2008) and movement patterns in response to prey densities would more likely take place in summer.

There is also evidence that Nile crocodiles undertake large-scale seasonal movements in response to spatial and temporal changes in prey abundance (Leslie 1997). Leslie (1997) suggested that Nile crocodile movement patterns in Lake St Lucia follow the migration patterns of striped mullet (Mugil cephalus), which do in fact move up the Rio Maputo during summer floods and have been found in pans as high up the river system as Lake Nyamithi (Kyle 2002). In either case, moving below the confluence of the Usuthu and Pongola rivers, fish concentrations would be concentrated in the comparatively narrow Rio Maputo channel before they enter the extensive floodplain system within NGR.
Crocodiles need to bask for longer durations in winter than in summer (Kofron 1993). Nile crocodiles move from the Rio Maputo floodplain and into NGR to take advantage of undisturbed basking sites, such as Lake Nyamithi (Pooley 1982). Densities in Lake Nyamithi peak in June and July, which correlates with the coldest time of the year. Densities then drop sharply after mating has taken place in August. Movement from the Rio Maputo into NGR, and Lake Nyamithi in particular, may be to access undisturbed basking and breeding sites.

\section{Home range}

This is only one of a few studies to calculate the home range of Nile crocodiles and comparative data is therefore lacking. However, similar to Hutton's (1989) study on the Nile crocodile and other studies on salt water crocodiles (Brien et al. 2008; Kay 2004b), no differences in home range between males and females during the dry season were found.

Thermal constraints often render ectotherms like crocodiles inactive for colder periods of the year, confining them to thermal refugia where they avoid periods of low resource availability (Madsen \& Shine 1996). Since both males and females are equally influenced by thermal constraints, it is not surprising that home ranges do not differ during the dry (cool) season. The home range of individuals within such thermal refugia would be expected to contract (Webb et al. 1982) and most studies on home range show a smaller home range during the dry season (Brien et al. 2008; Hutton 1989; Kay 2004b). However, home ranges for Nile crocodiles in NGR during the dry season were larger than those calculated by Hutton during the wet and dry season, despite Lake Ngezi having a surface area 3.5 times the magnitude of Lake Nyamithi. This could be due to the topography of the study site (Brien et al. 2008) and the high degree of connectivity in the Pongola floodplain (Calverley 2013), allowing crocodiles to move freely throughout the reserve, in addition to the fact that Lake Ngezi is a closed system.

In contrast to Hutton (1989), we found that home range increased with size (TL) and that adult Nile crocodiles (>2.5 m TL) occupied larger total home ranges than sub-adult crocodiles $(<2.5 \mathrm{~m} \mathrm{TL})$. Core areas where sub-adults spent $50 \%$ of their time made up a small percentage of their total home range, indicating highly localised use of home ranges. Adult Nile crocodiles made use of larger home ranges, with core areas constituting a larger percentage of total home range size, indicating more expansive use of home range areas. Generally, sub-adult Nile crocodiles were confined to Lake Nyamithi, while adults ranged widely throughout the Pongola floodplain, making use of riverine and lacustrine habitats.

The ability and inclination of crocodiles to move great distances between habitat patches is influenced by life history parameters such as size and sex as well as social interactions and predation threats. In Lake Nyamithi, sub-adult crocodiles were confined to the shallow inlets of the lake. Both Botha 
(2005) and Champion (2011) noted changes in the habitat use of Nile crocodiles in artificial water impoundments.

Only one of the telemetered Nile crocodiles captured in the Pongola system ventured into the Usuthu River system or Banzi Pan. This validates Ward's (1989) observation that populations within these two systems remain relatively independent of one another. Interestingly, the individual in question was located in the new course of the Usuthu River after it exits Banzi Pan and may signal greater mixing between the Usuthu and Pongola river populations in the future, due to the recent divergence of the Usuthu River.

\section{Territoriality}

Territorial behaviour of Nile crocodiles has been observed in numerous studies (Champion 2011; Garrick \& Lang 1977; Modha 1967; Pooley \& Gans 1976; Swanepoel 1999). However, territoriality as a component of crocodilian movement ecology is becoming increasingly questionable (e.g. Brien et al. 2008; Combrink 2014; Kay 2004b). By comparing the degree of home range overlap, territoriality can be investigated. For example, Kay (2004b) and Brien et al. (2008) found that home ranges of large male C. porosus overlapped extensively, concluding that territoriality was not displayed in their respective study areas, contrary to popular belief.

Some studies suggest that if territorial behaviour is displayed by Nile crocodiles, it may be suspended, facilitating largescale movement or migration at certain times of the year (Swanepoel 1999) as well as aggregations around basking sites during the non-breeding season and at areas of high prey density (Lang 1987). At NGR, the home range of Nile crocodiles overlapped extensively during the dry season, indicating a lack of territoriality. However, territorial displays or conflicts necessitate that individuals be in close proximity to one another and may be of very short duration (Garrick \& Lang 1977). Using the extent to which home ranges overlap as an indication of territoriality may therefore not be a suitable method.

\section{Management implications}

Studying the movement patterns of Nile crocodiles in NGR has contributed to understanding the role that the reserve plays in the conservation of the greater NGR-Rio Maputo Nile crocodile populations. The reserve acts as a winter refuge and spring breeding site for an estimated 846 crocodiles that also inhabit the Rio Maputo during the summer months. Interestingly, crocodiles are not content to remain within particular basking loci and range widely throughout the floodplain in winter.

Movement out of the reserve and into the Rio Maputo is thought to be in response to seasonal concentrations or migrations of prey items, which begins in November. Nile crocodiles then move back into NGR as water levels in the floodplain recede in May. As the Rio Maputo is more important for Nile crocodiles, especially their recruitment into the NGR than vice versa (Calverley 2013), it is strongly recommended that the Rio Maputo, or at least parts of it that are important as breeding sites, receive formal protection or at least compatible land use activities.

\section{Acknowledgments}

We are most grateful to the following people for their help in capturing and marking Nile crocodiles at NGR: F. Myburgh, C. Halkett-Siddal, G. Champion, J. Warner, B. Gumede and X. Combrink. For providing a vehicle, we thank The Ford Wildlife Fund. The Hans Hoheisen Charitable Trust and the Water Research Commission are thanked for financial assistance. C. Dearden is thanked for radio transmitter assembly and guidance. Ezemvelo KZN Wildlife kindly gave permission for the study. We had ethical clearance from the University of KwaZulu-Natal Ethics Committee.

\section{Competing interests}

The authors declare that they have no financial or personal relationships which may have inappropriately influenced them in writing this article.

\section{Authors' contributions}

P.M.C. (University of KwaZulu-Natal) and C.T.D. (University of KwaZulu-Natal) conceived the project. P.M.C. collected and analysed the data, P.M.C. and C.T.D. wrote the article, and C.T.D. sourced funding.

\section{References}

Botha, H., Van Hoven, W. \& Guillette, L.J. Jnr., 2011, 'The decline of the Nile crocodile population in Loskop Dam, Olifants River, South Africa', Water SA 37(1), 103-108. http://dx.doi.org/10.4314/wsa.v37i1.64109

Botha, P.J., 2005, 'The ecology and population dynamics of the Nile Crocodile Crocodylus niloticus in the Flag Boshielo Dam, Mpumalanga Province, South Africa', MSc thesis, University of Pretoria, Pretoria.

Brien, M.L., Read, M.A., McCallum, H.I. \& Grigg, G.C., 2008, 'Home range and movements of radio-tracked estuarine crocodiles (Crocodylus porosus) within a non-tidal waterhole', Wildlife Research 35, 140-149. http://dx.doi.org/10.1071/ WR06116

Brien, M.L., Webb, G., Manolis, C., Lindner, G. \& Ottoway, D., 2010, 'A Method for attaching tracking devices to crocodilians', Herpetological Review 41, 305-308.

Burt, W.H., 1943, 'Territoriality and home range concepts as applied to mammals', Journal of Mammalogy 24, 346-352. http://dx.doi.org/10.2307/1374834

Calverley, P., 2013, 'Conservation Ecology of the Nile Crocodile (Crocodylus niloticus) in the Ndumo Game Reserve in North Eastern KwaZulu-Natal and the Rio Maputo Floodplain in South Eastern Mozambique', PhD thesis, University of KwaZuluNloodplain in South East, Pietermaritzburg.
Nata

Calverley, P. \& Downs, C.T., 2014a, in press, 'Population status of Nile crocodiles in Ndumo Game Reserve, KwaZulu-Natal, South Africa (1971-2012)', Herpetologica. http://dx.doi.org/10.1655/HERPETOLOGICA-D-13-00090

Calverley, P. \& Downs, C.T., 2014b, in press, 'Habitat use by Nile crocodiles in Ndumo Game Reserve, South Africa: a naturally patchy environment', Herpetologica. http://dx.doi.org/10.1655/HERPETOLOGICA-D-13-00088

Campos, Z., Coutinho, M., Mourao, G., Bayliss, P. \& Magnusson, W.E., 2006, 'Long distance movements by Caiman crocodilus yacare: implications for management of the species in the Brazilian Pantanal', Herpetological Journal 16, 123-132.

Champion, G., 2011, 'The Ecology of Nile Crocodile (Crocodylus niloticus) in Pongolapoort Dam, Northern KwaZulu-Natal, South Africa', MSc thesis, University of KwaZulu-Natal, Pietermaritzburg.

Combrink, A.S., 2004, 'Population Status of Crocodylus niloticus (Nile Crocodile) at Lake Sibaya, Republic of South Africa', MSc thesis, University of KwaZulu-Natal, Pietermaritzburg.

Combrink, A.S., 2014, 'Spatial and reproductive ecology and population dynamics of the Nile Crocodile (Crocodylus niloticus) in the St Lucia Estuarine system, South Africa', PhD thesis, University of KwaZulu-Natal, Pietermaritzburg. 
Combrink, X., Korrûbel, J.L., Kyle, R., Taylor, R. \& Ross, P., 2011, 'Evidence of a declining Nile Crocodile (Crocodylus niloticus) population at Lake Sibaya, South Africa', South African Journal of Wildlife Research 41, 145-157. http://dx.doi. Africa', South African Journal
org/10.3957/056.041.0201

Combrink, X., Warner, J. \& Downs, C.T., 2013, 'Crocodiles', in R. Perissinotto, D.D. Stretch \& R.H. Taylor (eds.), Ecology and Conservation of Estuarine Ecosystems: Lake St Lucia as a Global Model, pp. 332-253, Cambridge University Press, Cambridge. http://dx.doi.org/10.1017/CBO9781139095723.019

Downs, C.T., Greaver, C. \& Taylor, R., 2008, 'Body temperature and basking behaviour of Nile crocodiles (Crocodylus niloticus) during winter', Journal of Thermal Biology 33, 185-192. http://dx.doi.org/10.1016/j.jtherbio.2008.02.001

Dutton, P., 1971, 'Some factors affecting the fluctuations of waterfowl populations on Lake Nyamithi', unpublished report, Natal Parks Board, Pietermaritzburg.

Fergusson, R., 2010, 'Wildlife survey phase 2 and management of human-wildlife conflicts in Mozambique', in Survey of Crocodile Populations in Mozambique, Vol. 2 Part 5., AGRECO G.E.I.E., Brussels, Belgium.

Ferreira, S.M. \& Pienaar, D., 2011, 'Degradation of the crocodile population in the Olifants River Gorge of Kruger National Park, South Africa', Aquatic Conservation: Marine and Freshwater Ecosystems 21(2), 155-164. http://dx.doi.org/10.1002/ Marine and 1175

Forbes, A.T. \& Demetriades, N.T., 2006, 'The benthos of Nyamithi Pan, Ndumo Game Reserve, KwaZulu-Natal', unpublished report for Ezemvelo KwaZulu-Natal Wildlife by Marine and Estuarine Research, Durban.

Franklin, C.E., Read, M.A., Kraft, P.G., Liebsch, N., Irwin, S.R. \& Campbell, H.A., 2009, 'Remote monitoring of crocodilians: implantation, attachment and release methods for transmitters and data-loggers', Marine and Freshwater Research 60 284-292. http://dx.doi.org/10.1071/MF08153

Games, I., 1990, 'The feeding ecology of two Nile crocodile populations in the Zambez Valley', PhD thesis, University of Zimbabwe, Harare.

Garrick, L.D. \& Lang, J.W., 1977, 'Social signals and behaviors of adult alligators and crocodiles', American Zoologist 17, 225-239. http://dx.doi.org/10.1093/ icb/17.1.225

Heeg, J. \& Breen, C.M., 1982, 'Man and the Pongola floodplain', National Scientific Programmes Unit: CSIR, SANSP Report 56, 1-129.

Hocutt, C.H., Loveridge, J.P. \& Hutton, J.M, 1992, 'Biotelemetry monitoring of translocated Crocodylus niloticus in Lake Ngezi, Zimbabwe', Journal of Zoology 226(2), 231-242. http://dx.doi.org/10.1111/j.1469-7998.1992.tb03836.x

Hutton, J.M., 1987, 'Growth and feeding ecology of the Nile crocodile Crocodylus niloticus at Ngezi, Zimbabwe', Journal of Animal Ecology 56, 25-38. http://dx.doi. org $/ 10.2307 / 4797$

Hutton, J.M., 1989, 'Movements, home range, dispersal and the separation of size classes in Nile crocodiles', American Zoologist 29(3), 1033-1049. http://dx.doi. org/10.1093/icb/29.3.1033

Hutton, J.M. \& Woolhouse, M.E.J., 1989, 'Mark-recapture to assess factors affecting the proportion of a Nile crocodile population seen during spotlight counts at Ngezi, Zimbabwe, and the use of spotlight counts to monitor crocodile abundance Journal of Applied Ecology 26, 381-395. http://dx.doi.org/10.2307/2404068

Kay, W.R., 2004a, 'A new method for attaching electronic devices to crocodilians', Herpetological Review 35(4), 354-357. http://dx.doi.org/10.2307/1564793

Kay, W.R., 2004b, 'Movements and home range of radio tracked Crocodylus porosus in the Cambridge Gulf region of Western Australia', Wildlife Research 31, 495-508. http://dx.doi.org/10.1071/WR04037

Kofron, C.P., 1993, 'Behavior of Nile crocodiles in a seasonal river in Zimbabwe', Copeid 2, 463-469. http://dx.doi.org/10.2307/1447146

Kyle, R., 2002, 'Interesting new record and further notes on the occurrence of marine fish in Nyamithi Pan, Ndumo Game Reserve, South Africa', Koedoe 45(2), 123-125. http://dx.doi.org/10.4102/koedoe.v45i2.29

Lang, J.W., 1987, 'Crocodilian behaviour: implications for management', in G.J.W. Webb, S.C. Manolis \& P.J. Whitehead (eds.), Wildlife Management: Crocodiles and Alligators, pp. 273-294, Beatty and Sons, Sydney.

Lang, J.W. \& Whitaker, S., 2010, 'Application of telemetry techniques in crocodilian research: Gharial (Gavialis gangeticus) spatial ecology in the Chambal River, India', in K. Sivakumar \& B. Habib (eds.), Telemetry in Wildlife Science, ENVIS Bulletin: Centre on Wildlife \& Protected Areas Bulletin, vol. 13, pp. 161-170, Wildlife Centre on Wildlife \& Protected Are

Leslie, A.J., 1997, 'The ecology and physiology of the Nile crocodile, Crocodylus niloticus, in Lake St. Lucia, KwaZulu-Natal, South Africa', PhD thesis, Drexel University, Philadelphia.

Leslie, A.J. \& Spotila, J.R., 2000, 'Osmoregulation of the Nile crocodile, Crocodylus niloticus, in Lake St. Lucia, KwaZulu-Natal, South Africa', Comparative Biochemistry and Physiology 126, 351-365. http://dx.doi.org/10.1016/S1095-6433(00)00215-4
Madsen, T. \& Shine, R., 1996, 'Determinants of reproductive output in female water pythons (Liasis fuscus: Pythonidae)', Herpetologica 52, 146-159.

Mathews, W.S., 1994, 'Hippo and crocodile counts in the northern KwaZulu-Natal region', unpublished report, Natal Parks Board, Pietermaritzburg.

Modha, M.L., 1967, 'The ecology of the Nile crocodile, Crocodylus niloticus Laurenti. 1786, on Central island, Lake Rudolph', East African Wildlife Journal 5, 74-95. http://dx.doi.org/10.1111/j.1365-2028.1967.tb00763.x

Nathan, R., Getz, W.M., Revilla, E., Holyoak, M., Kadmona, R., Saltze, D. et al., 2008, 'A movement ecology paradigm for unifying organismal movement research', Proceedings of the National Academy of Sciences USA, 105, 19052-19059. http:// dx.doi.org/10.1073/pnas.0800375105

Pooley, A.C., 1969, 'Preliminary studies on the breeding of the Nile crocodile, Crocodylus niloticus, in Zululand', Lammergeyer 10, 22-24.

Pooley, A.C., 1982, 'The ecology of the Nile crocodile, Crocodylus niloticus, in Zululand, South Africa', MSc thesis, University of Natal, Pietermaritzburg.

Pooley, A.C. \& Gans, C., 1976, 'The Nile crocodile', Scientific American 234, 114-124. http://dx.doi.org/10.1038/scientificamerican0476-114

Read, M.A., Grigg, G.C., Irwin, S.R., Shanahan, D. \& Franklin, C.E., 2007, 'Satellite tracking reveals long distance coastal travel and homing by translocated estuarine crocodiles, Crocodylus porosus', PloS ONE, 2(9), e949. http://dx.doi.org/10.1371/ journal.pone.0000949

Rogers, A.R. \& Carr, A.P., 1998, 'HRE: The home range extension for ArcView', Centre for Northern Forest Ecosystem Research, Ontario Ministry of Natural Resources, Canada.

Rootes, W.L. \& Chabreck, R.H., 1993, 'Cannibalism in the American alligator', Herpetologica 49, 99-107. http://dx.doi.org/10.1655/HERPETOLOGICA-D-1000040.1

Rubenstein, D.R. \& Hobson, K.A., 2004, 'From birds to butterflies: animal movement patterns and stable isotopes', Trends in Ecology and Evolution 19, 256-263. http:// dx.doi.org/10.1016/j.tree.2004.03.017

Russell, A.P., Bauer, A.M. \& Johnson, M.K., 2005, 'Migration in amphibians and reptiles: An overview of patterns and orientation mechanisms in relation to life history strategies', in A.M.T. Elewa (ed.), Migration of Organisms: Climate, Geography, Ecology, pp. 151-203, Springer, London. http://dx.doi.org/10.1007/3 540-26604-6_7

Seaman, D.E. \& Powell, R.A., 1996, 'An evaluation of the accuracy of kernel density estimators for home range analysis', Ecology 77, 2075-2085. http://dx.doi. org/10.2307/2265701

Seaman, D.E, Millspaugh, J.J., Kernohan, B.J., Brundige, G.C., Raedeke, K.J. \& Gitzen, R., 1999, 'Effects of sample size on kernel home range estimates', Journal of Wildlife Management 63, 739-747. http://dx.doi.org/10.2307/3802664

Strauss, M., Botha, H. \& Van Hoven, W., 2008, 'Nile crocodile Crocodylus niloticus telemetry: observations on transmitter attachment and longevity', South African
Journal of Wildlife Research 38(2), 189-192. http://dx.doi.org/10.3957/03794369-38.2.189

Swanepoel, D.J.G., 1999, 'Movements, nesting and the effects of pollution on the Nile Crocodile Crocodylus niloticus in the Olifants River, Kruger National Park', MSC thesis, University of Natal, Pietermaritzburg.

Thomas, B., Holland, J.D. \& Minot, E.O., 2010, 'Home range and movement patterns of an estuarine crocodile Crocodylus porosus: A satellite tracking pilot study', Northern Territory Naturalist 22, 60-74.

Thomas, B., Holland, J.D. \& Minot, E.O., 2011, 'Wildlife tracking technology options and cost considerations', Wildlife Research 38(8), 653-663. http://dx.doi. org/10.1071/WR10211

Van Vuuren, L., 2011, 'KwaZulu-Natal: It's man versus croc: conservation', Water Wheel 10(4), 13-18.

Wallace, K.M. \& Leslie, A.J., 2008, 'Diet of the Nile Crocodile (Crocodylus niloticus) in the Okavango Delta, Botswana', Journal of Herpetology 42(2), 361-368. http:// dx.doi.org/10.1670/07-1071.1

Ward, M.C., 1989, 'Aerial survey of Ndumo Game Reserve', unpublished report, Natal Parks Board, Pietermaritzburg.

Webb, G.J.W., Manolis, S.C. \& Buckworth, R., 1982, 'Crocodylus johnstoni in the McKinlay River Area, N.T.I. Variation in the diet, and a new method of assessing the relative importance of prey', Australian Journal of Zoology 30, 877-99. http:// the relative importance of prey',
dx.doi.org/10.1071/ZO9820877

Webb, G.J.W. \& Messel, H., 1977, 'Crocodile capture techniques', Journal of Wildlife Management 41, 572-575. http://dx.doi.org/10.2307/3800531

Worton, B.J., 1989, 'Kernel methods for estimating the utilization distribution in home-range studies', Ecology 70(1), 164-168. http://dx.doi.org/10.2307/1938423 


\section{Appendix 1 Detailed information on tracked Nile crocodiles}

The smallest Nile crocodile radio tagged was a $202 \mathrm{~cm}$ TL female (frequency 150.237). She remained in the capture area in the shallow north-eastern corner of Lake Nyamithi for the majority of the study, seldom moving from her chosen basking site.

The next largest Nile crocodile fitted with a transmitter was a $232 \mathrm{~cm}$ TL female (frequency 150.455). She was also caught in the north-eastern corner of Lake Nyamithi. However, one month later, she left Lake Nyamithi and entered the Pongola floodplain in the vicinity of iHotwe Pan and did not return to Lake Nyamthi. On 3 September 2009, 5 months after fitting the transmitter, she was located in the new course of the Usuthu River below Banzi Pan (Figure 1).

The smallest male fitted with a transmitter was $234 \mathrm{~cm}$ TL (frequency 150.196), captured on the mid southern shore of Lake Nyamithi on 24 March 2009. The following night the same individual was spotted within $100 \mathrm{~m}$ of the capture site and was not startled by the approaching boat. The night after that (26 March 2009), this same individual was nearly noosed again, by mistake (the crocodile was on the northern bank opposite the capture site). Tracking surveys over the next 5 months would show this to be a regular occurrence, with the male regularly moving from basking sights on the northern shore to basking sites on the southern shore. The maximum distance across the lake is $320 \mathrm{~m}$ at this point and the male stayed within a $500 \mathrm{~m}$ stretch of the shoreline on the northern and southern banks (Figure 1).

The next largest male Nile crocodile caught was $254 \mathrm{~cm}$ TL (frequency 150.215), captured in the western inlet of Lake Nyamithi on 27 March 2009. This part of the lake is only inundated during the wet season. The following day he was spotted $550 \mathrm{~m}$ from the capture sight on the northern shore of the lake, where he remained for 2 days. Following this he remained in the western half of the lake until June, when he moved into the old course of the Pongola River, in close proximity to the outlet of Lake Nyamithi, progressing to Bakabakha Pan, which is over $5.5 \mathrm{~km}$ from the capture site. In July he was back in the western half of the lake, where he remained until 06 September 2009 when signal was lost (Figure A1, Appendix 2).

A $281 \mathrm{~cm}$ TL male Nile crocodile was captured on 01 May 2009 in the north-western part of Lake Nyamithi. At 19:31 he was released with a radio transmitter attached (frequency 150.276). At 12:00 the following day he was successfully radio tracked and spotted basking on the north-eastern portion of the lake, over $1.5 \mathrm{~km}$ from the capture sight. He remained in this area until 29 May 2009, when he was tracked to the central part of Lake Nyamithi, where he remained for the duration of June and July. In August a location was obtained at Mavilo Hill - a historical nesting ground in the eastern periphery of the floodplain $5 \mathrm{~km}$ from the previous location. Two days after this, a location was obtained $6.4 \mathrm{~km}$ to the north-west at a concrete bridge across the new course of the Usuthu River, below Banzi Pan. On 12 November 2009 he was back in Lake Nyamithi, $6.5 \mathrm{~km}$ from the previous radio location. By 19 November 2009 he was located on the causeway at the outlet to Lake Nyamithi and 2 days later was back at Mavilo Hill (Figure A2, Appendix 3). After this, signal was lost.

Nile crocodile 295 was a $315 \mathrm{~cm}$ TL male (frequency 151.295) and was captured on 02 May 2009 in the north-eastern part of Lake Nyamithi. Five days later he had left Lake Nyamithi and was located at Bakabakha Pan, $3.8 \mathrm{~km}$ north-east in the Pongola floodplain. By 29 May 2009 he was at the entrance to Lake Nyamithi at the causeway and on 4 June 2009 was back in the western part of Lake Nyamithi, where he remained the until 26 June 2009 when he was located in the old course of the Pongola River, north of the outlet of Lake Nyamithi. He was not located again until August when he was once again found in Bakabakha Pan, where he remained until signal was lost on 30 August 2009 (Figure 1). This crocodile was never found in the central or western parts of Lake Nyamithi.

The next largest Nile crocodile was a $339 \mathrm{~cm}$ TL male (frequency 150.316), caught on 26 March 2009 in the western inlet of Lake Nyamithi. The following day he was located $1 \mathrm{~km}$ to the east but still in the western part of the lake. On 29 March 2009 he was located $3.3 \mathrm{~km}$ away at the outlet of Lake Nyamithi. The following day he was located in the old course of the Pongola River, $200 \mathrm{~m}$ south of the causeway. Signal was lost for one month and the next fix was back in Lake Nyamithi at Ndlozi Point, $1.9 \mathrm{~km}$ to the west. Five days later, on 04 June 2009, he was spotted back at the outlet of Lake Nyamithi. After this the transmitter was lost and he was identified by the unique colour-coded tags on nine further occasions throughout Lake Nyamithi until the end of September. It must be noted that resighting activities are only practical in open bodies of water or where a clear line of sight of basking individuals is possible. No resightings were obtained in the Pongola floodplain (Figure 1).

The largest Nile crocodile fitted with a transmitter was a 358 cm TL male (frequency 150.396), caught on 02 May 2009 in the western part of Lake Nyamithi. Three days later he was located at a known basking site, Deception Point (DP), on the southern shore of the lake, $1.2 \mathrm{~km}$ to the east and in the centre of the lake. For the next 24 days no locations were achieved. However, on 29 May 2009 he was again located at DP. By 18 August 2009 he was in Bakabakha Pan and remained there until 30 August 2009. On 31 August 2009 he was back at DP. In September he was located at Mavilo Hill, $5 \mathrm{~km}$ to the north-east in the Pongola floodplain, where he remained until signal was lost (Figure 1). 


\section{Appendix 2}

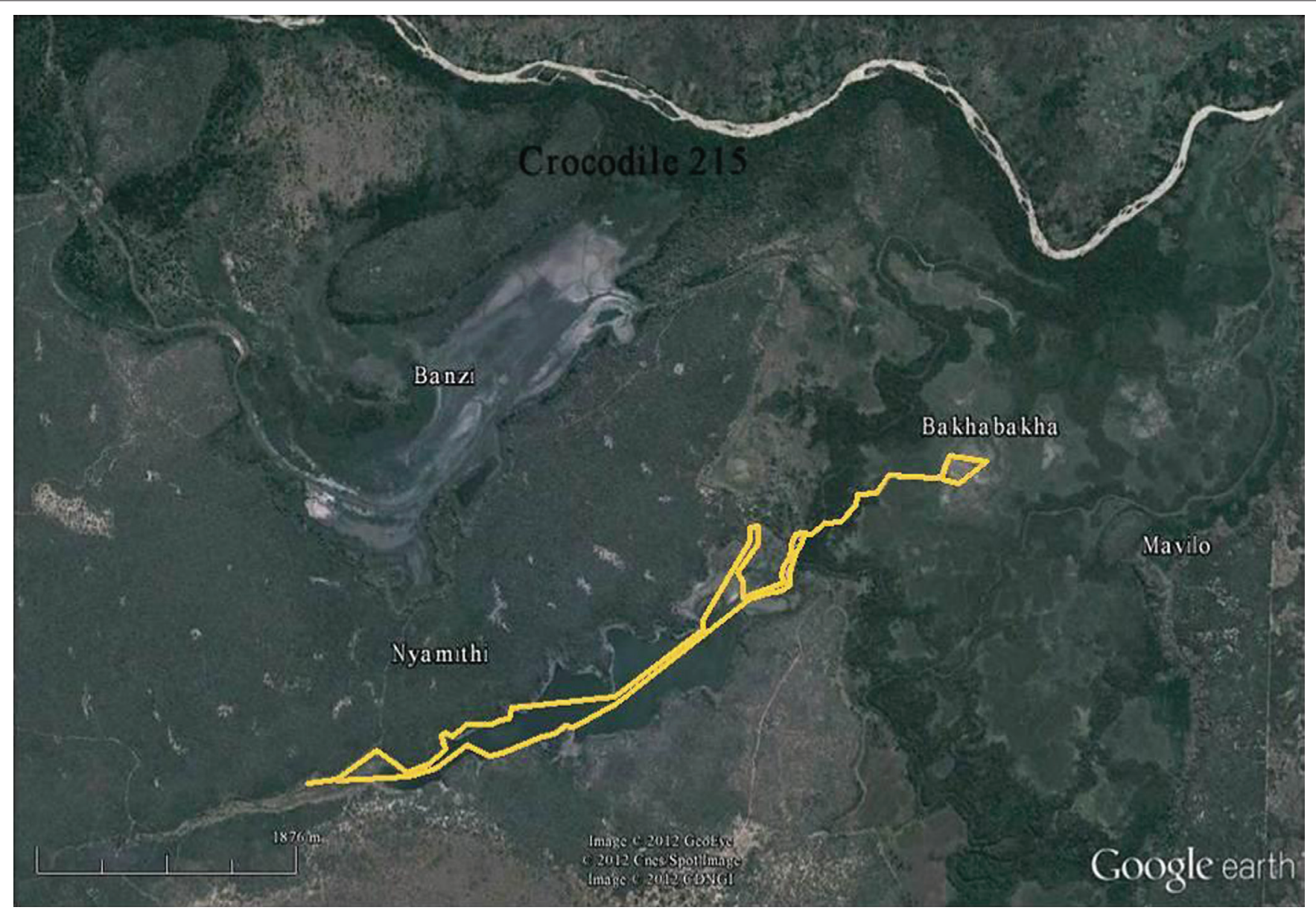

FIGURE A1: Home range of Nile crocodile 215 (yellow line) in Ndumo Game Reserve. 


\section{Appendix 3}

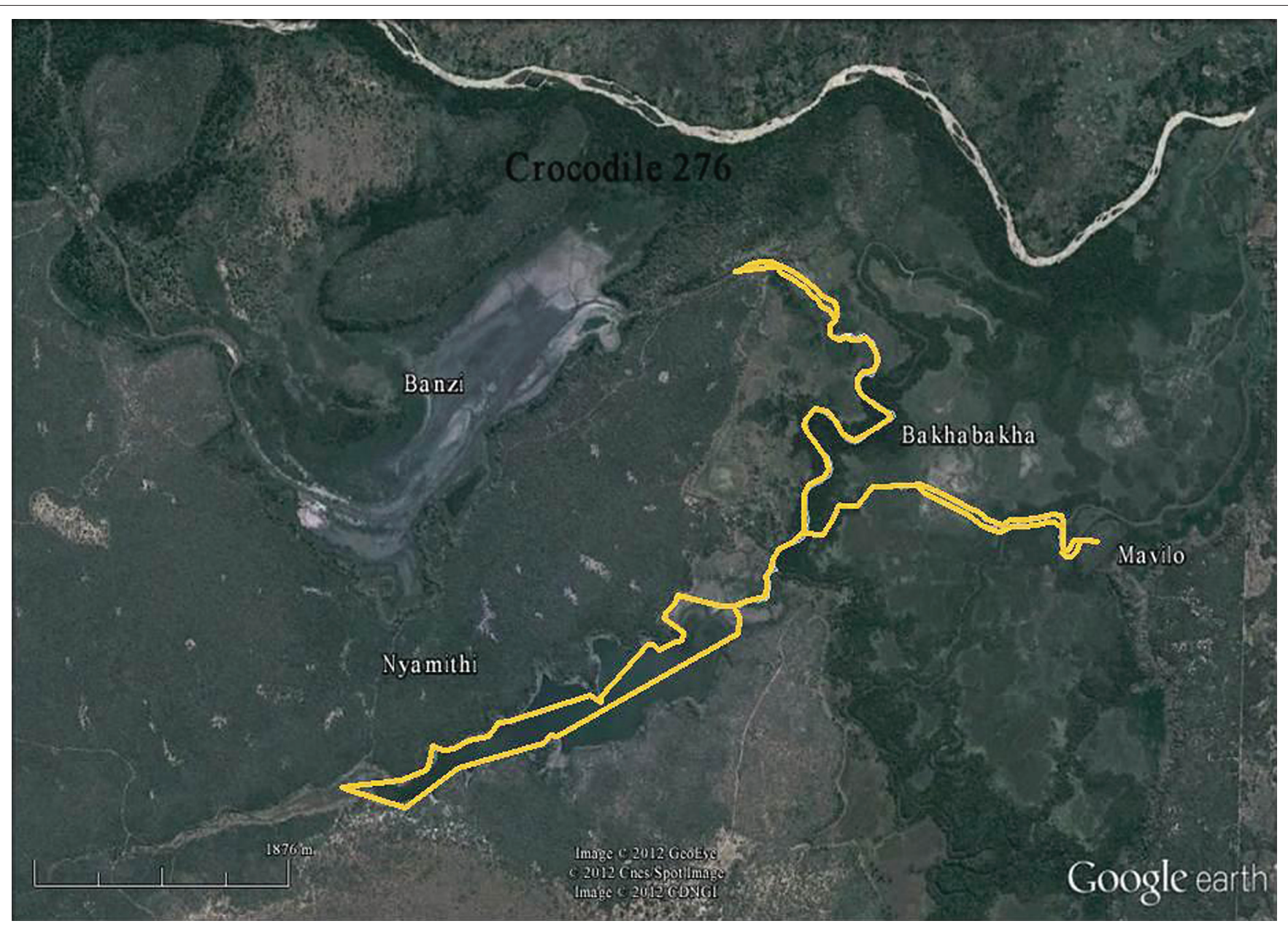

FIGURE A2: Home range of Nile crocodile 276 (yellow line) in Ndumo Game Reserve. 